Meta

Journal des tradlucteurs

Translators' Journal

\title{
Il faut qu'un fonds soit " ouvert » ou « fermé »...
}

\section{Paul A. Horguelin}

Volume 13, numéro 1, mars 1968

URI : https://id.erudit.org/iderudit/003107ar

DOI : https://doi.org/10.7202/003107ar

Aller au sommaire du numéro

Éditeur(s)

Les Presses de l'Université de Montréal

ISSN

0026-0452 (imprimé)

1492-1421 (numérique)

Découvrir la revue

Citer cet article

Horguelin, P. A. (1968). Il faut qu'un fonds soit « ouvert » ou « fermé »... Meta, 13(1), 26-27. https://doi.org/10.7202/003107ar d'utilisation que vous pouvez consulter en ligne.

https://apropos.erudit.org/fr/usagers/politique-dutilisation/ 


\section{IL FAUT QU'UN FONDS \\ SOIT "OUVERT" OU "FERMÉ" . .}

Les placements collectifs ou «fonds mutuels» jouissant depuis quelques années d'une grande faveur auprès des épargnants (pour ceux qui n'aiment pas le néologisme «investisseurs »), un vocabulaire nouveau est apparu en même temps que se développait cette nouvelle forme de placements. Si les traducteurs ont su trouver des équivalents acceptables pour des termes tels que loading charge, acquisition fee, break-up value, investment manager, growth stock, il semble si l'on en juge par les prospectus actuellement en circulation - qu'ils se soient heurtés à une autre difficulté plus sérieuse: la traduction de closed-end et open-end fund. Il s'agit de deux catégories distinctes de placements collectifs qu'un conseiller en placements définit de la façon suivante:

Some funds are called «open-end $\gg$ in the sense that the number of shares in investor's hands changes almost daily as they sell new shares and as shares are turned in for redemption. Both cost and redemption prices are

3. No 185 , p. 670 .

4. Poissy (Seine-et-Oise). Communications personnelles des 13 mai et 24 juin 1965.

5. Cf. l'édition anglaise du Catalogue Eaton de Noël, p. 177.

6. No 185 , p. 473 . 
based on the current market value of the securities owned by the fund. «Closed-end » funds, on the other hand, operate on their original capital (although it may be increased occasionally). Their shares trade on the stock exchanges and can be bought only from another shareholder; price is determined by market demand and not directly on the value of the securities owned by the fund.

Dans les prospectus que j'ai lus, on a traduit mutual «open-end» funds par «fonds mutuels dits open-end", ce qui ne peut être qu'une solution provisoire. Or, j'ai trouvé récemment dans le Dictionnaire commercial et financier de J.V. Servotte (Bruxelles, Éditions Brepols, 1959) les traductions suivantes: Open end investment trust - Fonds de placement à capital variable; Closed end investment trust - Fonds de placement à capital fixe. Je crois donc que l'on pourrait utiliser ces traductions et rendre, par exemple, mutual open-end (ou closed-end) investment company par société de placements collectifs à capital variable (ou fixe).

paul A. Horguelin 